\section{Commentary: The reality of The Society of Thoracic Surgeons risk calculators at high volume centers}

Alexander A. Brescia, MD, MSc, and

Gorav Ailawadi, MD, MBA

In a large single-center retrospective series, Johnston and colleagues ${ }^{1}$ report outcomes of low-risk surgical aortic valve replacement (SAVR) in 3474 patients between 2005 and 2017. The authors used Society of Thoracic Surgeons (STS) risk models and found observed-to-expected ratios of $<1$ for mortality $(0.27 ; 95 \%$ confidence interval [CI], $0.14-0.42)$, stroke $(0.65 ; 95 \% \mathrm{CI}, 0.41-0.89)$, and reoperation $(0.50 ; 95 \% \mathrm{CI}, 0.42-0.60)$.

Few will find it surprising that the Cleveland Clinic, one of the world's largest cardiac surgical centers, achieves SAVR outcomes superior to STS predictive models. Importantly, the authors also show that outcomes have improved over time for low-risk patients undergoing SAVR through a series of quality improvement efforts, including standardized preoperative screening and imaging protocols, intraoperative pump and cardioplegia protocols, a pre-chest closure checklist to reduce bleeding, early extubation protocols, and a Cardiac Medical Emergency Team all oriented toward standardization and patient safety. These findings are a testament to the impact of continuous quality improvement, even at an already high-volume, high-performance center. Similar efforts have been undertaken through statewide initiatives in Michigan $^{2,3}$ and Virginia ${ }^{4}$ and a nationwide collection of quality improvement collaboratives, thereby benefiting large patient populations. ${ }^{5}$ These studies have demonstrated that a significant amount of outcome variation is not explained through traditional STS risk models and instead may be related to patient selection, organizational structure, and

\footnotetext{
From the Department of Cardiac Surgery, University of Michigan, Ann Arbor, Mich. Disclosures: The authors reported no conflicts of interest.

The Journal policy requires editors and reviewers to disclose conflicts of interest and to decline handling or reviewing manuscripts for which they may have a conflict of interest. The editors and reviewers of this article have no conflicts of interest.

Received for publication March 9, 2021; revisions received March 9, 2021; accepted for publication March 10, 2021; available ahead of print March 16, 2021.

Address for reprints: Alexander A. Brescia, MD, MSc, Department of Cardiac Surgery, University of Michigan, Frankel Cardiovascular Center, 1500 E Medical Center Dr, Ann Arbor, MI 48109 (E-mail: abrescia@med.umich.edu).

J Thorac Cardiovasc Surg 2023;165:607-8

$0022-5223 / \$ 36.00$

Copyright (c) 2021 by The American Association for Thoracic Surgery

https://doi.org/10.1016/j.jtcvs.2021.03.035
}

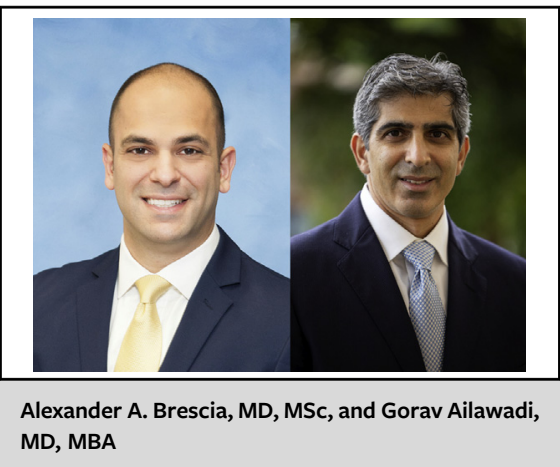

CENTRAL MESSAGE

Outperforming national risk models for surgical aortic valve replacement is achievable. Continued optimization of cardiac risk models is necessary to provide useful data for clinicians and patients.

care processes. ${ }^{6,7}$ Notably, lower-volume centers may not have the ability to select patients for SAVR in the same way as large referral centers but may be able to implement similar quality improvement techniques.

The authors indicate these data could provide a benchmark for transcatheter aortic valve replacement (TAVR). Recently published data showed that TAVR was superior to SAVR in low-risk patients with regard to a composite endpoint of death, stroke, or rehospitalization at 2 years in the randomized PARTNER 3 trial, which included patients from Cleveland Clinic and other high-volume centers. ${ }^{8}$ Notably, these findings require verification with longer-term follow-up as has been performed for SAVR. We advocate for a lifetime management approach to the aortic valve and make treatment decisions in conjunction with the heart team and through shared decision making with each patient, which results in most of our low-risk patients undergoing SAVR.

Lastly, the authors suggest that the substantial improvements in performance relative to the expected outcomes from STS risk models support the development of a "more agile 'real-time' risk tool, such as that being developed by the American Association for Thoracic Surgery Quality Gateway." In parallel, the STS also has initiated updates to the Adult Cardiac Surgery Database, including cloud-based technology and a similar plan to utilize realtime results. ${ }^{9}$ For more accurate modeling, it may be useful 
to add a procedure-specific operative volume variable to STS risk models to reflect the variable volume-outcome relationships exhibited across different cardiac surgical procedures. Further improvements to risk prediction also could involve machine learning and predictive modeling, as discussed by the authors, and may be best and most efficiently achieved in a collaborative fashion between the 2 major North American cardiothoracic societies.

\section{References}

1. Johnstone DR, Mahboudi R, Soltesz EG, Artis AS, Roselli EE, Blackstone EH, et al. Redefining "low risk": outcomes of surgical aortic valve replacement in low-risk patients in the transcatheter aortic valve replacement era. J Thorac Cardiovasc Surg. 2023;165:591-604.e3.

2. Likosky DS, Harrington SD, Cabrera L, DeLucia A III, Chenoweth CE, Krein SL, et al. Collaborative quality improvement reduces postoperative pneumonia after isolated coronary artery bypass grafting surgery. Circ Cardiovasc Qual Outcomes. 2018;11:e004756.
3. Milojevic M, Bond C, Theurer PF, Jones RN, Dabir R, Likosky DS, et al. The role of regional collaboratives in quality improvement: time to organize, and how? Semin Thorac Cardiovasc Surg. 2020;32:8-13.

4. Johnston LE, Downs EA, Hawkins RB, Quader MA, Speir AM, Rich JB, et al. Outcomes for low-risk surgical aortic valve replacement: a benchmark for aortic valve technology. Ann Thorac Surg. 2017;104:1282-8.

5. Likosky DS, Al-Attar PM, Malenka DJ, Furnary AP, Lehr EJ, Paone G, et al. Geographic variability in potentially discretionary red blood cell transfusions after coronary artery bypass graft surgery. J Thorac Cardiovasc Surg. 2014;148:3084-9.

6. Brescia AA, Rankin JS, Cyr DD, Jacobs JP, Prager RL, Zhang M, et al. Determinants of variation in pneumonia rates after coronary artery bypass grafting. Ann Thorac Surg. 2018;105:513-20.

7. Shih T, Zhang M, Kommareddi M, Boeve TJ, Harrington SD, Holmes RJ, et al. Center-level variation in infection rates after coronary artery bypass grafting. Circ Cardiovasc Qual Outcomes. 2014;7:567-73.

8. Leon MB, Mack MJ, Hahn RT, Thourani VH, Makkar R, Kodali SK, et al. Outcomes 2 years after transcatheter aortic valve replacement in patients at low surgical risk. J Am Coll Cardiol. 2021;77:1149-61.

9. The Society of Thoracic Surgeons. Next generation STS national database launches in 2020. Available at: https://www.sts.org/publications/sts-news/nextgeneration-sts-national-database-launches-2020. Accessed March 5, 2021. 